\title{
Progression of an iris melanoma over 41 years
}

\author{
David G Charteris
}

Princess Alexandra Eye Pavilion, Royal Infirmary of Edinburgh, Edinburgh EH3 9HA

D G Charteris

Correspondence to:

Mr D G Charteris,

Department of Pathology,

Institute of Ophthalmology, 17-25 Cayton Street, London ECIV 9AT.

Accepted for publication 10 April 1990
Figure 1: Appearance of the iris tumour in 1945. Note the small nodule peripherally between 2 and $3 o^{\circ}$ 'clock.

Figure 2: 1981 The tumour has enlarged and the lens is cataractous below.

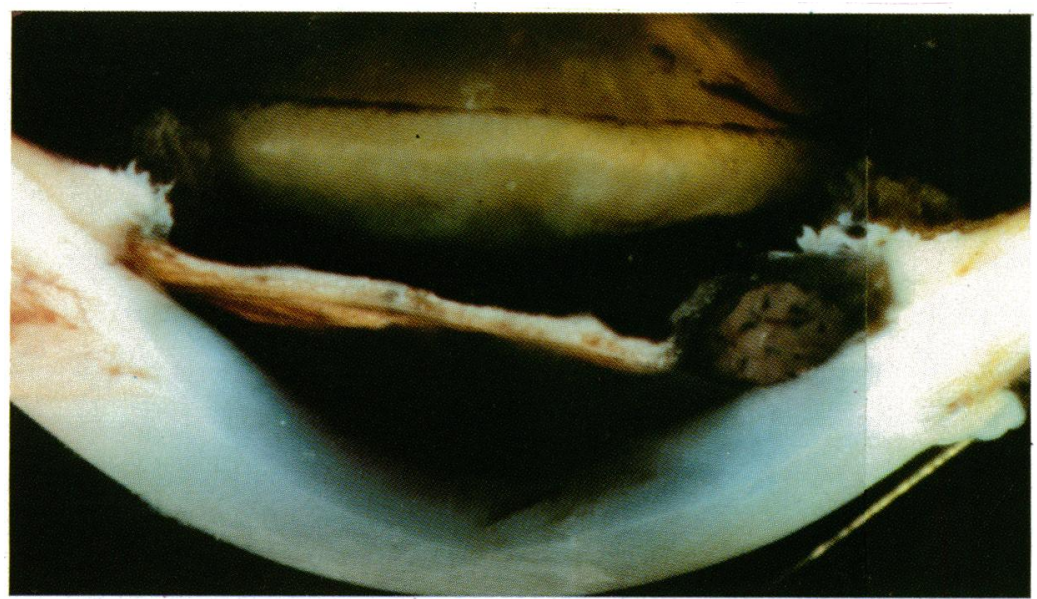

Figure 4: Macroscopic view of anterior segment showing tumour mass extending to drainage angle.

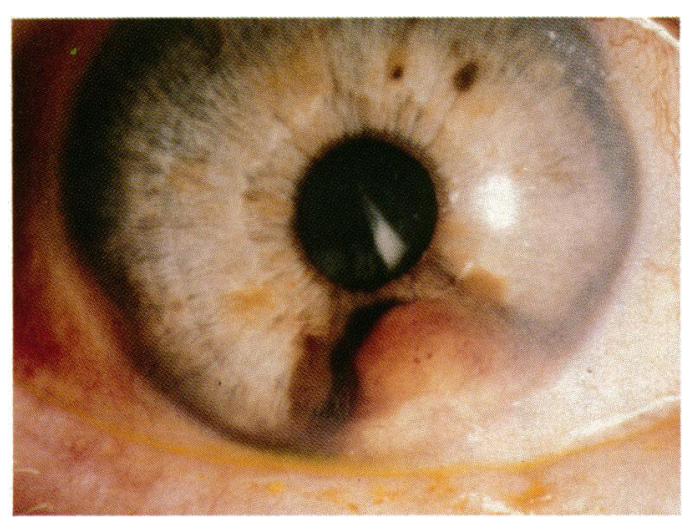

\begin{abstract}
An iris melanoma first recorded in 1945 progressed over a period of 41 years to produce secondary glaucoma resulting in enucleation. The case illustrates the advancing nature of such lesions.
\end{abstract}

In 1945 a 37-year-old woman was noted to have a vascularised iris tumour inferonasal in her right eye (Fig 1). The lesion extended to the drainage

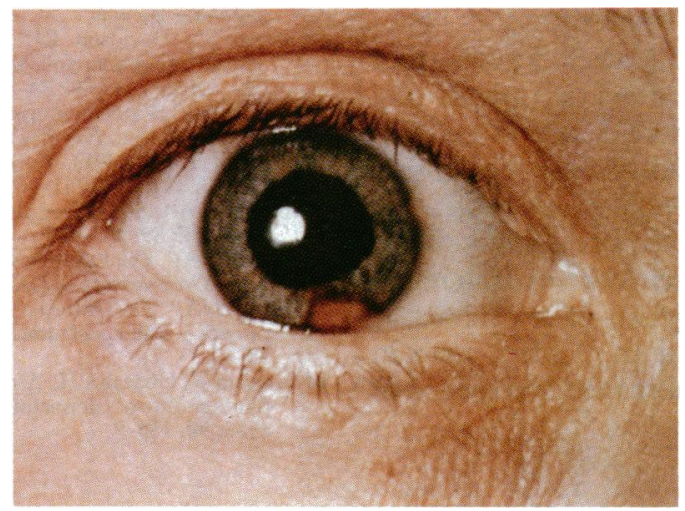

\section{Discussion}

The case emphasises the slowly progressive course of iris melanomas. ${ }^{1-7}$ The lesion appeared fairly static for 30 years. It then spread round the angle to form a ring melanoma and was complicated by recurrent haemorrhage. Apparent lack of growth of iris melanocytic tumours may be due to very slow enlargement which can remain clinically undetectable over some years. ${ }^{6}$ The slow progression of the tumour supports the current trend towards more conservative management of iris tumours, ${ }^{46}$ the decision to enucleate being made because of intractable glaucoma. The change in behaviour may well reflect a change towards a more malignant cell type. ${ }^{45}$ The case also provides an interesting early example of the use of colour photography to record clinical appearances.

The financial support of the Ross Foundation for Prevention of Blindness (Scotland) is gratefully acknowledged. 


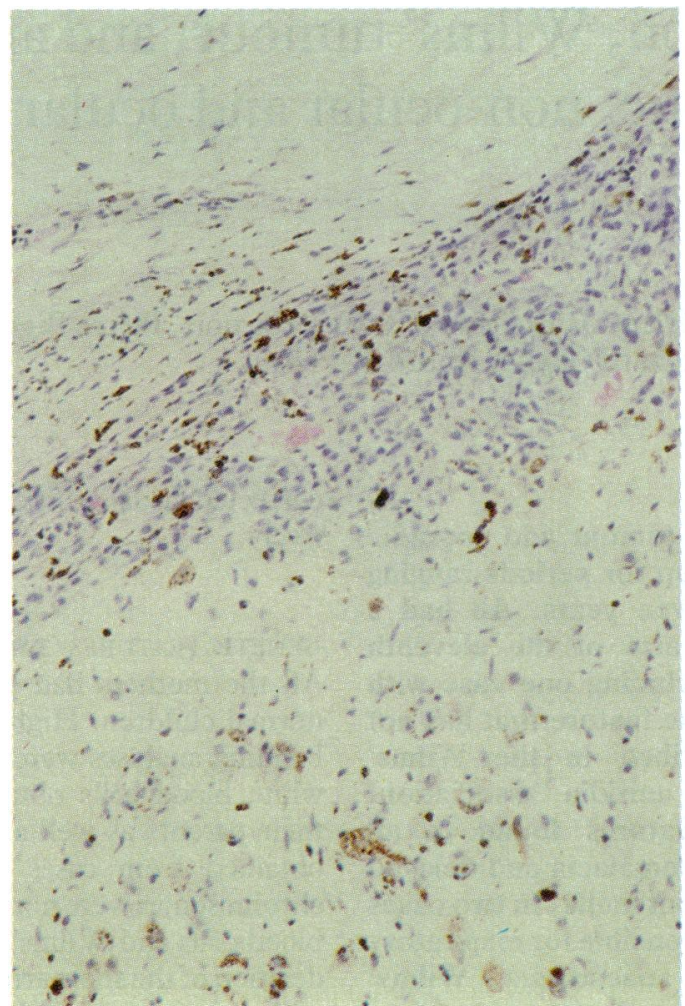

Figure 5: Photomicrograph showing lightly pigmented iris melanoma invading drainage angle structures. $(H-E, \times 100$.)

1 Duke JR, Dunn SN. Primary tumours of the iris. Arch Ophthalmol 1958; 59: 204-14.

2 Rones B, Zimmerman LE. The prognosis of primary tumours of the iris treated by iridectomy. Arch Ophthalmol 1958;60: 193-205.

3 Ashton N. Primary tumours of the iris. Br F Ophthalmol 1964; 48: $650-68$.

4 Jakobiec FA, Silbert G. Are most iris 'melanomas' really nevi?

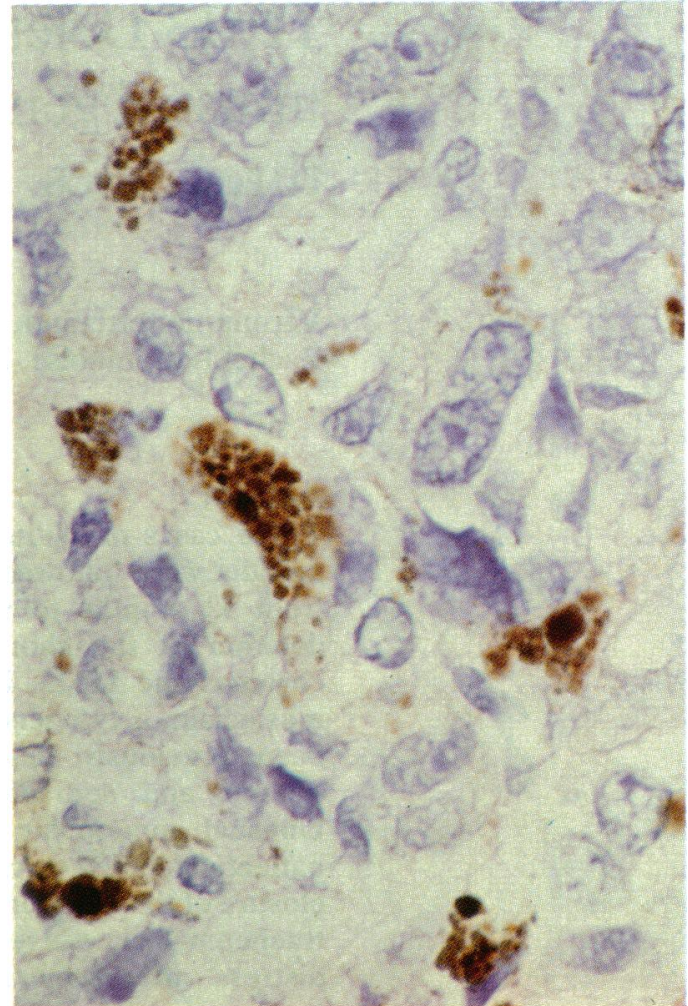

Figure 6: Higher power photomicrograph of spindle $B$ iris malignant melanoma. $(H-E, \times 400$. $)$

Arch Ophthalmol 1981; 99: 2117-32.

5 Geisse LJ, Robertson DM. Iris melanomas. Am 7 Ophthalmol 1985; 99: 638-48.

6 Territo C, Shields CL, Shields JA, Augsburger JJ, Schroeder RP. Natural course of melanocytic tumours of the iris. Ophthalmology 1988; 95: 1251-5.

7 McGalliard JN, Johnston PB. A study of iris melanoma in Northern Ireland. Br $\mathcal{F}$ Ophthalmol 1989; 73: 591-5. 